\title{
Sexual Exploitation of Women with Schizophrenia
}

\author{
Dr. Mary V. Seeman, MD \\ Professor Emerita, Department of Psychiatry, University of Toronto, Ontario, Canada \\ mary.seeman@utoronto.ca
}

Abstract:

Background: Vulnerable populations are sometimes targets for violence and sexual exploitation; this has been reported with respect to women with serious mental illnesses such as schizophrenia. Aim: The aim of this review is to summarize the recent literature on this topic and to outline promising strategies for prevention. Method: Relevant search terms were used in the Google Scholar database from 2000 to the present, and 50 English language papers were selected for review. Results: Women with schizophrenia are targets for sexual harassment and violence, not only domestically, but also on the street, and in institutions. Perpetrators can be intimate partners, strangers, and hospital or prison staff. Women with schizophrenia are sometimes sextrafficked. They are vulnerable because of isolation, passivity, cognitive defects, psychotic symptoms, substance abuse, homelessness, and poverty, and, as a consequence of exploitation, they suffer shame and guilt, increased severity of psychotic symptoms, and increased risk of sexually transmitted disease, unwanted pregnancy, and abortion. On psychiatric assessment, they are seldom asked about the practice of survival sex or about sexual exploitation, and seldom disclose these aspects of their life. Clinical programs are beginning to become available that address self-stigma, educate about risk factors for sexual exploitation and teach safety and self-defense as well as conflict resolution. Psychiatric services are instituting screening procedures for employees, appropriate staff education, and improvements in surveillance measures and policies. Conclusion: Because of increasing awareness of harassment and exploitation of women in general, there is mounting concern about women made more vulnerable than others as a result of severe mental illness.

Keywords: Severe mental illness; Sexual exploitation; Violence; Prevention

\section{INTRODUCTION}

Sexual coercion and exploitation of vulnerable populations - children, the elderly, the physically disabled, the mentally disabled, the poor and the gullible - are major societal problems throughout the world. Both sexes are at risk, but the likelihood of victimization is highest among women. The multiple disabilities of women with severe mental illness appear to render them especially vulnerable to such exploitation. Disabled persons are known to experience significantly more violence (physical, sexual and intimate partner violence and stalking/ harassment) than those without disability, as shown in a recent Australian study of more than 17,000 adults (Krnjacki et al., 2016). This study noted gender differences: women with disabilities were more likely to experience sexual and partner violence whereas men with disabilities were more likely to experience physical violence. A 2012 systematic review of this topic had already reached the same conclusion (Hughes et al., 2012). In the United States, 36\% of women with disabilities report intimate partner violence (Hahn et al., 2014; Mitra and Moradian, 2014). Women with psychological disabilities are targeted more than others by both intimate partners and non-domestic perpetrators (Plummer and Findlay, 2012). Non-domestic violence is reportedly three times as prevalent in the United Kingdom (UK) in those with mental illness compared to those without (Khalifeh et al., 2013). In the Netherlands, both men and women with severe mental illness are reportedly targets for criminal violence (Kamperman et al., 2014) and this has been shown elsewhere as well (Chapple et al., 2004; Coverdale and Turbott, 2000; Maniglio, 2009; Mauritz et al., 2013; Teasdale, 2009).

This paper reviews sexual exploitation of women with schizophrenia-related disorders in order to determine prevalence, risk factors, sequelae, and preventive measures.

www.arjonline.org

Page 22 


\section{METHOD}

For this narrative review, relevant search terms severe mental illness OR schizophrenia OR psychosis AND sexual exploitation OR sexual abuse OR sexual violence OR victimization OR sex trafficking were applied to the Google Scholar post-2000 database (English only publications). The most recent publication on the specific topic addressed was preferentially selected. For the final version of this review, 50 relevant papers were used.

\section{RESULTS AND DiscusSiON}

\section{Prevalence of sexual victimization of women with severe mental illness}

Khalifeh et al. (2015) surveyed 303 SMI (severe mental illness) patients who were in psychiatric treatment using the British Crime Survey domestic/sexual violence questionnaire. They compared responses with those of 22, 606 general population controls and found that sexual assaults (by anyone) were reported by $61 \%$ of SMI women versus $21 \%$ of general population women. Past-year sexual assault was reported by $10 \%$ of the women with SMI and $2.0 \%$ of the control women. Among both the patients and the controls, women had a 6-9-fold risk over men of being victims of sexual violence.

Kamperman et al. (2014) found a smaller female/male ratio. Their female SMI outpatients had a three times greater annual risk of becoming victims of sexual harassment or sexual assault than their male counterparts. Among 75 female patients with schizophrenia from Turkey (Hacioglu Yildirim et al., 2014), the rates of traumatic events were as follows: physical abuse (81.4\%), emotional abuse (78.6\%), emotional neglect (55.7\%), sexual harassment (28.6\%), and sexual abuse (24.3\%). The rate for abuse among homeless female patients with SMI was as high as $97 \%$. Khalifeh et al. (2016) synthesized the evidence of 30 studies (1610 SMI participants) on prevalence, odds, and risk factors for recent violence, with a focus on domestic and sexual violence. The prevalence of recent domestic violence ranged from $15-22 \%$ among women and from $4-10 \%$ among men, a 6-fold higher odds of victimization when compared with the general population.

\section{Sexual exploitation of SMI women within psychiatric or penal services}

Warner et al. (2004) found high levels of sexual activity among inpatients on acute psychiatric wards, raising concern as to what should constitute consent under such circumstances in light of the fluctuating nature of decisional capacity in many psychiatric illnesses. Thirty of the 100 patients in the Warner et al. study sample had engaged in some form of sexual activity, a portion of which was reported as non-consensual. Among sexually active patients in a high security hospital (Hales et al., 2006), found very little evidence of coercion into unwanted relationships. Frueh et al. (2005), however, discovered in their survey that $8 \%$ of adult psychiatric patients reported sexual assault in psychiatric settings. Lawn and McDonald (2009) reported that sexual harassment and assault were an ongoing concern on psychiatric wards. A more recent one-year survey in Australia found that $85 \%$ of females felt unsafe during their stay on a psychiatric ward. Sixty-seven percent reported being subjected to sexual or other forms of harassment. Almost half (45\%) of the respondents in this survey had experienced sexual assault during an in-patient admission (Victorian Mental Illness Council, 2013). Since harassment and assault are rarely asked about during psychiatric assessment (a study by Read et al. (2006) suggests that $80 \%$ of female patients who had undergone sexual abuse were not asked about it when assessed) and is often not willingly reported (Banja, 2017; Rice 2008; Symonds and Oldham, 2014), it is impossible to know the true frequency of such events, some of which reportedly involve not only co-patients, but also staff members and visitors. One study of sexual violence in long-term care facilities found that $43 \%$ of the offenders were employees while $41 \%$ were residents. The care settings surveyed in that study included assisted living facilities, psychiatric facilities, group homes, and long-term-care facilities (Symonds and Oldham, 2014). 


\section{Sexual Exploitation of Women with Schizophrenia}

In prisons, the mentally ill are known to be targets for sexual violence, especially when they are women. Among inmates who self-reported a mental disorder, sexual victimization over the previous 6-month period was three times as high among female inmates (23.4\%) as among male inmates (8.3\%) (Wolff et al., 2007). These numbers may underestimate the problem because prisoners are reluctant to report victimization, especially when the perpetrators are members of staff (Fazel et al., 2016).

\section{Why Women With SMI Suffer Sexual Exploitation}

Striking correlations with victimization have been found in SMI women (Maniglio, 2009), chief among which are substance abuse and homelessness, both of which increase vulnerability to exploitation. Women with SMI, as a group, are known to use and abuse alcohol and drugs more than women in the general population (Hartz et al., 2014). Violent victimization is especially prevalent in dual diagnosis patients (psychosis plus substance abuse) (de Waal et al., 2018). De Waal et al. studied a large group of dual diagnosis patients, $60.1 \%$ of whom reported violent victimization (physical abuse, sexual assault or threats) in the past 12 months. Females were at higher risk than males.

Because of disturbing behaviors, persons with psychotic disorders are sometimes evicted both from their family homes and their rented apartments, ending up on the street or in homeless shelters, which exposes them to the dangers of violence, substance abuse, and exchange (or survival) sex. Laporte et al. (2018) conducted a study in Paris, France, which showed that one third of the homeless in that city had at least one psychiatric disorder; one fifth were alcohol-dependent; $18 \%$ were drug users. On psychiatric assessment, $13 \%$ were diagnosed with psychotic disorders. The rate of psychosis was ten times that of the general French population. According to a review of six studies on this topic (Roy et al., 2014), homeless women face significantly higher rates of violence than women who are housed, the lifetime rate of victimization among the homeless ranging from $74 \%$ to $87 \%$. Purser et al. (2017), using secondary data, examined the relationship of days and number of times a person has been homeless to involvement in survival sex. Survival sex is the trading of sex for food, shelter, drugs, or money. Among homeless individuals, a total of 141 respondents (15.65\%) were reported to have engaged in this risky behavior. The length of homelessness and number of homeless episodes, as well as a current age between 26 and 35, previous drug use, depression, and previous time spent in hospitals, increased the odds of engaging in survival sex (this was more true for men than women). Homelessness brings vulnerable people, especially those who engage in high risk behavior, to the attention of predators. Predators take advantage of the homeless and mentally ill on the assumption that their situation makes reporting violence unlikely and that, should it be reported, it will not be believed (Tyler et al., 2004). In some studies, up to $25 \%$ of homeless youth have admitted engaging in survival sex. Thirty-five percent reported having been sexually victimized. Tyler and Johnson (2006) are of the opinion that many young people engage in survival sex not only because they see no alternative, but also because they are frequently manipulated and coerced into it.

Many women report that they become involved in prostitution through force or through drug addiction (Kopetz et al., 2015; Middleton et al. 2018) and many of these women have a serious mental illness. In London, UK, 15 percent of sex-trafficked persons between 2006 and 2012 who were in contact with mental health services met criteria for schizophrenia and related disorders (Oram et al., 2015). These women are made vulnerable by isolation, unfilled affective needs, poverty and subsequent food and accommodation needs, as well as the demands of drug addiction. Once drawn into prostitution, they are often kept there through the use of force and coercion, food deprivation, beatings, rape, threats, drugs, and torture (Bigelson and Vuotto, 2013; Farley, 2009; Hudson and Nandy, 2012).

Middleton et al. (2018) report that as many as $41.2 \%$ of homeless youth in one central region of the United States were victims of sex trafficking; the figure was $47.6 \%$ for the women in the sample. Nearly three quarters reported a current mental health problem or diagnosis, with more than half reporting more than one. Over 


\section{Sexual Exploitation of Women with Schizophrenia}

$10 \%$ reported their diagnosis to be schizophrenia. A little under half of the respondents had received treatment for their mental health disorders. Of the 62 male respondents, 32.3\% reported being a sex trafficking victim. The age of first sex trafficking victimization was 16 and ranged from 12 to 23 years. The most common reason for their situation was cited by the survey respondents as coercion to perform a sexual act in exchange for money or for a place to stay or for food or drugs, clothes or protection.

Women with severe mental illness are vulnerable to abuse because their illness often isolates them, undermines their cognitive reasoning, evokes apathy on one hand, making them easier to persuade, and delusions and hallucinations on the other hand, so that they find it difficult to distinguish between the real and unreal. Their illness renders them susceptible to substance abuse, distances them from family and friends, puts an end to education, plunges them into poverty and unsafe neighborhoods and insecure housing. They feel powerless, and are convinced anything they say will not be believed. They perceive authority figures as untrustworthy, so they do not disclose private concerns (Rice, 2008). Their male contacts are men whose self-esteem is probably low and who, therefore, are all the more likely to engage in behavior that gives them the illusion of power over vulnerable others (Thakker and Ward, 2011). The victims begin to think of themselves as unworthy, even evil (Horsselenberg et al., 2016; Perese, 2007), so become passive in the face of aggression.

\section{Sequelae of sexual exploitation of women with SMI}

Many sequelae of sexual exploitation in this population have been reported. Violence and rape lead to diminished self-respect and symptoms of posttraumatic stress disorder (PTSD) (Lommen and Restifo, 2009; Lundberg et al., 2012; Mueser et al., 2004). Human immunodeficiency virus (HIV) infection may result from unwanted sexual contact (Singh et al., 2009), and so may unwanted pregnancy and induced abortion (Simoila et al., 2018). There may also be an increase in psychotic symptoms. Hacioglu Yildirim et al. (2014) found significantly higher scores on the Positive and Negative Syndrome scale in women with schizophrenia who had been exposed to sexual assault compared to their unexposed peers.

Another study highlighted not only increased schizophrenia symptoms post assault (hallucinations, blunted affect, and social withdrawal), but also the presence of clinical features that were new for the person, such as hostility, anxiety, anger and difficulty delaying gratification (Fortugno et al., 2013).

\section{Prevention of sexual exploitation of women with SMI}

The efficacy of interventions with women with SMI who have been sexually violated has not yet been shown in randomized controlled trials. These interventions focus on the reduction of self-stigmatizing attitudes (Mittal et al., 2012), psychoeducation about the nature of mental illness (in oneself and in potential perpetrators), awareness of risk factors, the learning of safety and self-defense skills and conflict resolution skills, as well as principles of social cognition (de Waal et al., 2015; van der Stouwe et al., 2016).

Outpatient commitment has been found to reduce victimization, the reduced vulnerability mediated, it has been theorized, via improved medication adherence and reduced substance abuse (Hiday et al., 2002). In treatment settings, preventive interventions include improved employee background checks, screening of visitors, increased surveillance on inpatient wards (video monitors), increased staff/patient ratios, staff education, accessible functioning call buttons, and improved policies and practices (Banja, 2014; Foster et al., 2007; Quinn and Happel, 2015; United States Government, 2011).

\section{CONCLUSION}

There is increased awareness globally about sexual harassment and exploitation of women. Women with schizophrenia are especially vulnerable because of social isolation, passivity, cognitive defects, psychotic symptoms, substance abuse, homelessness, unemployment, and poverty. They are abused by intimate partners, 
on the street, and sometimes in hospital during treatment for their mental symptoms. They sometimes engage in survival sex, trading sexual favors for accommodation, for food, clothes, or for the drugs to which they are addicted. Women with schizophrenia are sometimes sex-trafficked, coerced to work in the sex trade for the monetary benefit of their traffickers. The consequences of exploitation for these women are lowered selfesteem, heightened psychotic symptoms, increased risk of sexually transmitted disease including HIV, unwanted pregnancy and induced abortion. During psychiatric assessment, the women are seldom asked about sexual exploitation and seldom disclose it to their clinicians, with the result that it remains invisible. Only recently are clinical programs beginning to become available that address the self-stigma of women with severe mental illness who are sexually exploited, educate them about risk factors, and teach safety and self-defense as well as conflict resolution skills that aid in prevention. Psychiatric services are beginning to institute screening procedures for employees, to provide appropriate staff education, and to make much-needed improvements in surveillance measures and care policies. These new interventions are only now beginning to be tested for effectiveness.

\section{REFERENCES}

1. Banja JD. Failures of foreseeability: Risk management considerations in reducing allegations of sexual violence in psychiatric units. J Healthc Risk Manag. 2017;36:21-5.

2. Banja JD. Preventing sexual attacks in healthcare facilities: Risk management considerations. J Healthc Risk Manag. 2014;33:5-12.

3. Bigelsen J, Vuotto S. Homelessness, survival sex, and human trafficking: As experienced by the youth of Covenant House New York. 2014. https://www.nn4youth.org/wp-content/uploads/Homeless-Youth-andTrafficking-Data-NN4Y-7-2-2014.pdf Accessed March 26, 2018.

4. Chapple B, Chant D, Nolan P, Cardy S, Whiteford H, McGrath J. Correlates of victimisation amongst people with psychosis. Soc Psychiatry Psychiatr Epidemiol. 2004;39:836-40.

5. Coverdale JH, Turbott SH. Sexual and physical abuse of chronically ill psychiatric outpatients compared with a matched sample of medical outpatients. J Nerv Ment Dis. 2000;188:440-5.

6. de Waal MM, Kikkert MJ, Blankers M, Dekker JJ, Goudriaan AE. Selfwise, other-wise, streetwise (SOS) training: A novel intervention to reduce victimization in dual diagnosis psychiatric patients with substance use disorders: Protocol for a randomized controlled trial. BMC Psychiatry. 2015;15:267.

7. deWaal MM, Christ C, Dekker JJM, Kikkert MJ, Lommerse NM, van den Brink W, et al. Factors associated with victimization in dual diagnosis patients. J Subs Abuse Treatment. 2018;84:68-77.

8. Farley M. Theory versus reality: Commentary on four articles about trafficking for prostitution. Womens Stud Int Forum. 2009;32:311-15.

9. Fazel S, Hayes AJ, Bartellas K, Clerici M, Trestman R. The mental health of prisoners: a review of prevalence, adverse outcomes and interventions. Lancet Psychiatry. 2016;3:871-81.

10. Fortugno F, Katsakou C, Bremner S, Kiejna A, Kjellin L, Nawka P, et al. Symptoms associated with victimization in patients with schizophrenia and related disorders. PLoS One. 2013;8:e58142.

11. Foster C, Bowers L, Henk N. Aggressive behaviour on acute psychiatric wards: prevalence, severity and management. J Adv Nurs. 2007;58:140-9.

12. Frueh BC, Knapp RG, Cusack KJ. Patientsí reports of traumatic or harmful experiences within the psychiatric setting. Psychiatr Serv. 2005;56:1123-33. 


\section{Sexual Exploitation of Women with Schizophrenia}

13. Hacioglu Yildirim M, Yildirim EA, Kaser M, Guduk M, Fistikci N, Cinar O, et al. The relationship between adulthood traumatic experiences and psychotic symptoms in female patients with schizophrenia. Compr Psychiatry. 2014;55:1847-54.

14. Hahn JW, McCormick MC, Silverman JG, Robinson EB, Koenen KC. Examining the impact of disability status on intimate partner violence victimization in a population sample. J Interpers Violence. 2014;29:3063-85.

15. Hales H, Romilly C, Davison S, Taylor PJ. Sexual attitudes, experience and relationships amongst patients in a high security hospital. Crim Behav Ment Health. 2006;16:254-63.

16. Hartz SM, Pato CN, Medeiros H, Cavazos-Rehg P, Sobell JL, Knowles JA, et al. Comorbidity of severe psychotic disorders with measures of substance use. JAMA Psychiatry. 2014;71:248-54.

17. Hiday VA, Swartz MS, Swanson JW, Borum RH, Wagner R. Impact of outpatient commitment on victimization of people with severe mental illness. Am J Psychiatry. 2002;159:1403-11.

18. Horsselenberg EMA, van Busschbach JT, Aleman A, Pijnenborg GHM. Self-stigma and its relationship to schizophrenia spectrum disorders. PLoS ONE. 2016;11:e0149763.

19. Hudson AL, Nandy K. Comparisons of substance abuse, high-risk sexual behavior and depressive symptoms among homeless youth with and without a history of foster care placement. Contemp Nurse. 2012;42:178-86.

20. Hughes K, Bellis M, Jones L, Wood S, Bates G, Eckley L, et al. Prevalence and risk of violence against adults with disabilities: A systematic review and meta-analysis of observational studies. Lancet. 2012;379:1621-9.

21. Kamperman AM, Henrichs J, Bogaerts S, Lesaffre EMEH, Wierdsma AI, Ghauharali RRR, et al. Criminal victimisation in people with severe mental illness: A multi-site prevalence and incidence survey in the Netherlands. PloS One. 2014;9:e91029.

22. Khalifeh H, Howard L, Osborn D, Moran P, Johnson S. Violence against people with disability in England and Wales: Findings from a national cross-sectional survey. PLoS One. 2013;8:e55952.

23. Khalifeh H, Moran P, Borschmann R, Dean K, Hart C, Hogg J, et al. Domestic and sexual violence against patients with severe mental illness. Psychol Med. 2015;45:875-86.

24. Khalifeh H, Oram S, Osborn D, Howard LM, Johnson S. Recent physical and sexual violence against adults with severe mental illness: a systematic review and meta-analysis. Int Rev Psychiatry. 2016;28:433-51.

25. Kopetz CE, Collado A, Lejuez CW. When the end (automatically) justifies the means: Automatic tendency toward sex exchange for crack cocaine. Motivation Sci. 2015;1:233-43.

26. Krnjacki L, Emerson E, Llewellyn G, Kavanagh AM. Prevalence and risk of violence against people with and without disabilities: findings from an Australian population-based study. Aust NZ J Public Health. 2016;40:16-21.

27. Laporte A, Vandentorren S, Détrez M-A, Douay C, Le Strat Y, Le Méner E, et al. Prevalence of mental disorders and addictions among homeless people in the greater Paris area, France. Int J Environ Res Public Health. 2018;15:241.

28. Lawn T, McDonald E. Developing a policy to deal with sexual assault on psychiatric in-patient wards. Psychiatr Bull. 2009;33: 108-11.

29. Lommen MJ, Restifo K. Trauma and posttraumatic stress disorder (PTSD) in patients with schizophrenia or schizoaffective disorder. Community Ment Health J. 2009;45:485-96. 
30. Lundberg P, Johansson E, Okello E, Allebeck P, Thorson A. Sexual risk behaviours and sexual abuse in persons with severe mental illness in Uganda: A qualitative study. PLoS ONE. 2012;7:e29748.

31. Maniglio R. Severe mental illness and criminal victimization: a systematic review. Acta Psychiatr Scand. 2009;119:180-91.

32. Mauritz MW, Goossens PJ, Draijer N, van Achterberg T. Prevalence of interpersonal trauma exposure and trauma-related disorders in severe mental illness. Eur J Psychotraumatol. 2013;4:1-15.

33. Middleton JS, Gattis MN, Frey LM, Roe-Sepowitz D. Youth experiences survey (YES): Exploring the scope and complexity of sex trafficking in a sample of youth experiencing homelessness. J Soc Serv Res. 2018. doi: $10.1080 / 01488376.2018 .1428924$

34. Mitra M, Mouradian VE. Intimate partner violence in the relationships of men with disabilities in the United States: Relative prevalence and health correlates. J Interpers Violence. 2014;29:3150-66.

35. Mittal D, Sullivan G, Chekuri L, Allee E, Corrigan PW. Empirical studies of self-stigma reduction strategies: A critical review of the literature. Psychiatr Serv. 2012;63:974-81.

36. Mueser KT, Salyers MP, Rosenberg SD, Goodman LA, Essock SM, Osher FC, et al. Interpersonal trauma and posttraumatic stress disorder in patients with severe mental illness: demographic, clinical, and health correlates. Schizophr Bull. 2004;30:45-57.

37. Oram S, Khondoker M, Abas M, Broadbent M, Howard LM. Characteristics of trafficked adults and children with severe mental illness: a historical cohort study. Lancet Psychiatry. 2015;2:1084-91.

38. Perese EF. Stigma, poverty and victimization: Roadblocks to recovery for individuals with severe mental illness. J Am Psychiatr Nurs Assoc. 2007;13:285-95.

39. Plummer SB, Findley PA. Women with disabilitiesí experience with physical and sexual abuse: Review of the literature and implications for the field. Trauma Abuse Violence. 2012;13:15-29.

40. Purser GL, Mowbray OP, O'Shields J. The relationship between length and number of homeless episodes and engagement in survival sex. J Soc Serv Res. 2017;43:262-9.

41. Quinn C, Happell B. Exploring sexual risks in a forensic mental health hospital: Perspectives from patients and nurses. Issues Ment Health Nurs. 2015;36:669-77.

42. Read J, McGregor K, Coggan C, Thomas DR. Mental health services and sexual abuse: The need for staff training. J Trauma Dissociation. 2006;7:33-50.

43. Rice E. The invisibility of violence against women diagnosed with schizophrenia: a synthesis of perspectives. Adv Nurs Sci. 2008;31:9-21.

44. Roy L, Crocker AG, Nicholls TL, Latimer EA, Ayllon AR. Criminal behavior and victimization among homeless individuals with severe mental illness: a systematic review. Psychiatr Serv. 2014;65:739-50,

45. Simoila L, Isometsä E, Gissler M, Suvisaari J, Sailas E, Halmesmäki E, et al. Schizophrenia and induced abortions: A national register-based follow-up study among Finnish women born between 1965-1980 with schizophrenia or schizoaffective disorder. Schizophr Res. 2018;192:142-7.

46. Singh D, Berkman A, Bresnahan M. Seroprevalence and HIV-associated factors among adults with severe mental illness - a vulnerable population. S Afr Med J. 2009;99:523-7.

47. Symonds A, Oldham J. Sexual assault can happen in your institution: Are you prepared? Nurs Manag. 2014;45:30-7. 
48. Teasdale B. Mental disorder and violent victimization. Crim Justice Behav. 2009;36:513-35.

49. Thakker J, Ward T. An integrated theory of sexual reoffending. Psychiatry Psychol Law. 2011;19:236-48.

50. Tyler KA, Johnson KA. Trading sex: Voluntary or coerced? The experiences of homeless youth. J Sex Res. 2006;43:208-16.

51. Tyler KA, Whitbeck LB, Hoyt DR, Cauce AM. Risk factors for sexual victimization among male and female homeless and runaway youth. J Interpers Violence. 2004;19:503-20.

52. United States Government Accountability Office.VA Health Care: Actions needed to prevent sexual assaults and other safety incidents, GA0-11-530.Washington, DC: June 2011. http://www.gao.gov/ assets/320/319342.pdf Accessed March 26, 2018.

53. van der Stouwe ECD, de Vries B, Aleman A, Arends J, Waarheid C, Meerdink A. et al. BEATVIC, a bodyoriented resilience training with elements of kickboxing for individuals with a psychotic disorder: Study protocol of a multicenter RCT. BMC Psychiatry 2016;16:227.

54. Victorian Mental Illness Awareness Council. Zero tolerance for sexual assault: A safe admission for women. 2013. http://www.daru.org.au/wp/wp-content/uploads/2013/05/Zero-Tolerance-for-Sexual-Assult_ VMIAC.pdf Accessed March 26, 2018.

55. Warner J, Pitts N, Crawford MJ, Serfaty M, Prabhakaran P, Amin R. Sexual activity among patients in psychiatric hospital wards. J R Soc Med. 2004;97:477-9.

56. Wolff N, Blitz CL, Shi J. Rates of sexual victimization in prison for inmates with and without mental disorders. Psychiatr Serv. 2007; 58:1087-94.

Citation: Dr. Mary V. Seeman, MD “Sexual Exploitation of Women with Schizophrenia”. American Research Journal of Addiction and Rehabilitation; 2(1); pp: 1-8

Copyright (C) Dr. Mary V. Seeman, MD. This is an open access article distributed under the Creative Commons Attribution License, which permits unrestricted use, distribution, and reproduction in any medium, provided the original work is properly cited. 